\title{
CG CENTRO AUTOMOTIVO: COMO FÊNIX, RESSURGIR DAS CINZAS ERA NECESSIDADE'
}

CG AUTOMOTIVE CENTER: LIKE FÊNIX, RISE FROM THE ASHES WAS A NECESSITY

Recebido em 31.10.2017. Aprovado em 04.09.2018

Avaliado pelo sistema double blind review

DOI: http://dx.doi.org/10.12712/rpca.v12i4.12482

\section{Marilia Azevedo da Silva}

mariliaa_azevedo@hotmail.com

Universidade do Vale do Itajaí (UNIVALI), Itajaí/SC, BRASIL

ORCID: https://orcid.org/0000-0001-7111-2745

\section{Mônica Cristina Rovaris Machado}

monicarovarisdoutorado@gmail.com

Universidade do Vale do Itajaí (UNIVALI), Itajaí/SC, BRASIL

ORCID: https://orcid.org/0000-0001-6661-2657

\section{Elaine John}

elaine_j8@hotmail.com

Universidade do Vale do Itajaí (UNIVALI), Itajaí/SC, BRASIL

ORCID: https://orcid.org/0000-0003-0224-3607

\section{Resumo}

A CG Centro Automotivo iniciou seu negócio no ano de 1990 e atua há 27 anos no mercado. Atualmente comercializa produtos e presta serviços automotivos relacionados a toda parte de acessórios, aros e pneus, mecânica, lataria e pintura. O caso traz à tona a trajetória da empresa e um pouco de sua jornada, expondo uma situação crítica de crise, em que o gestor cria uma alternativa: terceirizar alguns setores. A partir dessa prática e após um tempo de terceirização, uma determinada empresa deixa de ser terceirizada e torna-se concorrente direta desta, na loja em frente, a aproximadamente dez metros da CG Centro Automotivo. Diante desta situação totalmente inesperada, o gestor primeiramente entende o ocorrido e logo se depara com algumas questões: $\mathrm{O}$ que deve ser feito? Quais decisões devem ser tomadas? Quais caminhos devem ser seguidos?

Palavras-chave: Estratégia Organizacional. Terceirização. Caso para ensino.

\section{Abstract}

The CG Automotive Center began its business in the year of 1990 and has been acting for 27 years in the market. Currently it markets products and provides automotive services of any part of auto accessories, rims and tires, mechanics, bodywork and painting. The case brings up the trajectory of the enterprise and a little of its journey, exposing a critical situation of crisis in which the manager believes an alternative: outsource some sectors. From this practice and after a time of outsourcing, a determined enterprise stops its contract of outsourcing and become a competing company in the store in front of his. In the face of this totally unexpected situation, the manager first understands what happened and then comes up with some questions: What should be done? What decisions should be made? Which paths should be followed?

Keywords: Organizational Strategy. Outsourcing. Cases for Teaching.

\footnotetext{
${ }^{1}$ A empresa CG Centro Automotivo é uma organização fictícia.
} 


\section{Introdução}

Era uma manhã ensolarada de terça-feira, pontualmente às 8 hs, Rogério tinha um dia cheio, pois iria receber visitas de novos fornecedores e da equipe de marketing, para programar a nova campanha publicitária da CG Centro Automotivo.

Rogério, sempre muito simpático, chega na empresa cumprimentando os funcionários, pega um café e entra em sua sala, logo recebendo a notícia de que o setor terceirizado mais lucrativo iria deixar sua empresa e se mudar, em 30 dias, para a loja em frente.

- Bom dia, sr. Rogério! Será que você tem dez minutinhos para conversarmos? -questiona Alberto.

Apesar de estar com a agenda lotada, Rogério responde:

- Mas é claro. Diga, Alberto!

- Apenas vim avisá-lo de que, dentro de 30 dias, vou deixar a sua empresa e irei me mudar para a loja da frente, diz Alberto.

- Como? É você que vai para a loja da frente? Essa construção de meses é sua e você não me contou nada? - indaga Rogério, um pouco confuso.

- Sim! Apenas estou lhe informando que eu e minha equipe do setor de aros e pneus não iremos mais fazer parte da sua empresa - responde Alberto, logo saindo da sala com um pouco de pressa.

Nesse momento, Rogério, mais confuso ainda, começa a refletir e lhe surgem muitas dúvidas em mente. Como conseguir um gestor terceirizado, especializado no setor de aros e pneus, à altura de Alberto? O que fazer com a concorrência em frente à loja? Como atender seus clientes com o setor totalmente desestruturado?

\section{Nascendo e renascendo: A origem e trajetória}

A CG Centro Automotivo iniciou suas atividades em 1990, por meio da venda de peças de carros usadas, foi se transformando ao longo do tempo, até que, em um momento no ano de 1994, começou a comercializar alguns tipos de acessórios automotivos (além das peças usadas), já que o seu mix de produtos" não era mais tão interessante, pois o mercado havia mudado as suas necessidades.
A empresa começou a crescer, e em 1998, resolveu mudar o seu segmento, aplicando mudanças estratégicas também no corpo diretor da empresa e passando a comercializar somente acessórios automotivos. Novamente foi uma decisão acertada, pois a demanda de mercado era muito grande, os produtos forneciam uma boa lucratividade para a empresa e, principalmente, visibilidade, visto que a empresa possuía um grande apelo publicitário e uma boa estratégia de marketing. Tornou-se, então, bastante conhecida no mercado, destacando-se em relação à concorrência.

Nesse contexto, diante de várias estratégias adotadas, a empresa dobrou de tamanho e trouxe prospecção de mercado, graças ao verão de 2000/2001, por meio da chegada de argentinos na região da grande Florianópolis. Naquela época, era interessante o comércio direcionado aos argentinos, pois sua moeda estava muito valorizada. Esse fato aumentou o número de turistas, os quais se tornaram consumidores em potencial da CG.

Isto foi fantástico para a área comercial, mas a empresa não estava preparada para crescer tanto e tão rapidamente. Assim, começaram a surgir alguns problemas na área administrativa, que teve como consequência uma crise financeira na empresa, em 2005, em que passou por grandes dificuldades na gestão administrativa. Isso a obrigou a reduzir o quadro de 65 funcionários para 13, com o objetivo de evitar uma falência.

Além de a empresa ter que enxugar o número de colaboradores, ela precisou se reinventar, reestruturando-se drasticamente para poder se manter no mercado.

Sendo assim, a CG Centro Automotivo não chegou a falir e precisar "fechar as portas", mas a um ponto crucial em que ficou muito pequena em termos de faturamento, de estrutura e de prospecção de mercado. Apesar disso, continuou com uma boa imagem no mercado e uma boa quantidade de clientes, mesmo tendo que diminuir o seu mix de produtos e a sua capacidade de comercialização.

A quase falência obrigou o gestor Rogério a diminuir os custos da empresa, mantendo um faturamento mínimo para sobreviver e pagar as obrigações.

A CG Centro Automotivo não possuía capital. O gestor estava descapitalizado, e a empresa não possuía grande estoque. Por outro lado, precisava voltar a 
crescer, pois tinha oportunidade de crescimento, mas, sem uma gestão de capital, isso seria impossível.

Após uma reorganização da empresa em 2008, foram unidos alguns fatores, como a sua boa clientela, um bom espaço físico e a ausência de capital de giro. Assim, o gestor teve a ideia de terceirizar algumas áreas da empresa. Já que trabalhava no setor automotivo e somente com acessórios, ele percebeu que esses acessórios eram apenas uma das partes de prestação de serviços veiculares, podendo desenvolver outros setores como: mecânica, aros e pneus, lataria e pintura, martelinho de ouro, ar condicionado e lavação veicular.

\section{Entrando em auto-combustão: uma nova estratégia}

Rogério sempre teve um espírito empreendedor, garra, determinação e força de vontade e, ao se deparar com aquela situação ruim, pensou em terceirizar alguns setores.

Ao invés de oferecer diretamente os outros serviços, o que demandava investimentos e riscos, através de uma boa aceitação de mercado e muita credibilidade, desenvolveu um trabalho de captação de terceirizados, com empresas de um universo diferente do que a CG já oferecia.

Sendo assim, a CG possuía muito nome, espaço físico e ausência de capital, e as empresas terceirizadas, que tinham capital para investir, não tinham nome, estratégia de como se desenvolver, nem capital físico. Foi assim que o gestor enxergou a oportunidade de oferecer produtos e serviços para unir e agregar ao seu mix e foi buscar parceiros nos segmentos.

Esse projeto teve início em 2008, e em 2009 a empresa já havia se tornado um grande centro automotivo, em que a base principal era o setor de acessórios, que trazia em torno de 60 veículos por dia para o complexo. A empresa terceirizada de aros e pneus trazia 15 carros por dia; a oficina mecânica, dez clientes por dia; a oficina de lataria e pintura, 15 carros por semana, devido à demora do serviço; e o martelinho de ouro e ar condicionado não traziam muito fluxo de veículos, porém, mostravam atratividade aos clientes, já que o grande foco da empresa sempre foi comodidade, ou seja, ter tudo que o cliente precisa para o seu carro em um só lugar.

Essa estratégia de terceirização deu muito certo, pois essas empresas parceiras tinham respaldo e credibilidade muito forte no mercado, tinham uma gestão de marketing e publicidade fortíssima, desenvolvida pela própria CG. Além disso, o fato de oferecer todos os serviços em um só lugar aumentou o movimento de clientes da CG, havendo uma troca entre as empresas, pois o cliente, que inicialmente vinha consumir acessórios, descobria que existia uma gama de outros produtos e serviços, e vice-versa.

Sendo assim, para o mercado, a CG era uma empresa única, um complexo automotivo, muito forte e muito sólido, sendo um shopping que oferecia diversos segmentos. Além disso, com boas estratégias e bons processos internos, o cliente não percebia uma diferenciação de empresas.

Essa estratégia de terceirização deu muito certo, apesar de algumas empresas desistirem da parceria, pela diferença entre a forma de gestão empresarial do gestor terceirizado e do gestor da CG, ou seja, pela dificuldade de trabalhar em conjunto.

Algumas empresas cresceram, se fortaleceram e se expandiram dentro da CG. Tanto é que, uma dessas empresas, que iniciou de uma forma muito precária, sem capital, mas com bastante conhecimento e know how, durante os quatro anos em que esteve dentro do complexo, aprendeu muito com a forma como a Centro Automotivo agregava o mix de produtos e serviços. Assim como a própria empresa também aprendeu muito com o gestor terceirizado, pois este possuía grandes estratégias e era um bom empresário.

Em 2013, a empresa terceirizada de aros e pneus se viu dependente de uma estrutura para se expandir. Ela se encontrava limitada dentro desse espaço físico. Devido a esse fator, ela arranjou uma estratégia: sair de dentro do complexo e montar o seu próprio negócio e sua própria estrutura.

A empresa terceirizada montou sua loja do outro lado da rua, ou seja, em frente à loja com a qual possuía uma parceria, com as mesmas características e as mesmas cores da CG, para dar a impressão de que faziam parte da mesma empresa.

Existia uma regra inserida no contrato entre as partes (contratada e contratante/terceirizado e terceirizador), que descrevia o negócio como um mix automotivo, ou seja, todas as empresas do complexo tinham um fator em comum, que era o de comercializar produtos e serviços automotivos. Porém, havia um acordo de que ninguém poderia invadir o nicho do mercado do outro. 
Quem trabalhava com aros e pneus possuía exclusividade, assim como os acessórios, a mecânica, lataria e pintura, martelinho de outro, e assim por diante. Havia um relacionamento complementar, definindo com o quê cada empresa trabalharia e quais seriam os seus mix de produtos/serviços oferecidos.

Além do acordo de inexistência de concorrência interna, Rogério, criador do Centro Automotivo, não poderia solicitar o desligamento de algum terceirizado para que ele próprio prestasse aquele determinado tipo de serviço.

Por outro lado, as empresas terceirizadas poderiam solicitar o desligamento no momento em que desejassem. Nesse caso, após a saída do próprio terceirizado, o gestor poderia investir naquele ramo, por meio de investimento próprio ou através de outra empresa terceirizada.

O fato ocorrido foi que uma dessas empresas terceirizadas, que comercializava aros e pneus, correspondendo a $60 \%$ do faturamento mensal do segmento de terceirizados e que também contribuía com $60 \%$ no pagamento de aluguel, resolveu sair.

Existiam cinco terceirizados, sendo que um único terceirizado, de aros e pneus, era responsável por mais da metade do faturamento mensal de todos os terceirizados.

\section{Renascendo das cinzas: um novo começo}

Com a saída desse terceirizado, a situação da CG se complicou, pois os custos do complexo continuavam altos, mas a receita que a terceirizada de Alberto gerava já não existia mais.

O comunicado veio com 30 dias de antecedência, pouco tempo hábil para o Auto Shopping se organizar e contratar outro terceirizado de aros e pneus. A CG observara a construção e a criação de uma nova loja do outro lado da rua, sem saber quem era o responsável por aquele novo empreendimento.

Dessa forma, dentro do prazo legal, com 30 dias de antecedência o gestor do Auto Shopping foi comunicado pelo próprio gestor terceirizado de que ele iria terminar a parceria e mudar-se para o outro lado da rua. Nessa ocasião, Alberto questiona se Rogério tem 10 minutos para conversarem e o gestor responde positivamente.
- Apenas vim avisar que, dentro de 30 dias, vou deixar a sua empresa e irei me mudar para a loja da rua da frente -, diz Alberto.

Confuso, Rogério pensa em diversas alternativas e estratégias para a situação atual.

Com o surgimento dessa nova unidade, Alberto precisava de colaboradores, e por isso levou consigo alguns dos principais funcionários da CG já treinados e capacitados durante anos, oferecendo-lhes salários mais altos e benefícios a mais, para poder atraí-los.

Alberto levou para sua nova unidade Sílvio, o antigo coordenador de vendas de acessórios da CG, que trabalhava na empresa desde 1995, há 13 anos como funcionário. Atraiu também mais sete funcionários, sendo vendedores e instaladores, inclusive Vitor, que era o melhor, o mais competente e mais rápido instalador.

Nesse contexto, Alberto montou sua própria estrutura, para não ter mais o custo dentro do Centro Automotivo e poder expandir seu espaço. Ele sabia que a CG não tinha especialidade em aros e pneus e teria dificuldade em encontrar outro terceirizado capacitado e competente dentro desse segmento. Dessa forma, imaginava captar os clientes do Centro Automotivo, causando problemas em toda a estrutura da empresa.

Dessa forma, durante os quatro anos de parceria, a CG desenvolveu um concorrente do mesmo nível e da mesma altura do que a própria empresa, debaixo das suas asas.

Com a saída desse terceirizado, a empresa se viu em uma situação complicada, já que não recebia mais aquela receita mensal; não ofertava mais o produto que o cliente estava acostumado a utilizar; não tinha conhecimento e know how para montar o negócio, e não possuía tempo hábil para oferecer os produtos e serviços para os clientes.

Além de todos esses fatores, perdeu oito funcionários antigos e capacitados, e o mercado pensava que as duas empresas eram únicas. Por isso, os clientes consumiam no concorrente achando que estavam comprando na própria empresa.

Quando Alberto deixou a CG, sua empresa do outro lado da rua já estava funcionando a pleno vapor, oferecendo, além de aros e pneus, acessórios e mecânica, enquanto a empresa de Rogério estava sem o setor de aros e pneus para ofertar aos clientes. 
- Mas, Alberto, por que você não me comunicou antes? - perguntou Rogério em vOz alta, enquanto Alberto ia saindo da sala, já fechando a porta.

\section{Dilema - A Fênix renasce?}

Vendo-se em uma situação complicada, pois a CG não tinha know how para desenvolver o setor de aros e pneus, além de ter perdido funcionários e uma empresa terceirizada, Rogério se pergunta: como proporcionar o serviço de aros e pneus aos clientes? Como não deixar a concorrência atrapalhar? $\mathrm{O}$ que fazer daqui para a frente?

Diante desse contexto, Rogério precisava tomar uma atitude. Por isso, analisou todas as variáveis e pensou: qual seria a melhor alternativa a ser tomada?

\section{Notas de ensino}

\section{Utilização e recomendações do caso de ensino}

O público deste caso para ensino são alunos do curso de graduação em Administração e cursos tecnológicos na área de Gestão Organizacional. Sugere-se que o tema seja trabalhado em disciplinas relacionadas a estratégias organizacionais, principalmente vinculadas aos temas: desenvolvimento de estratégias, terceirização e tomada de decisões. Contudo. outras aplicações poderão ser desenvolvidas, tais como, empreendedorismo e análise mercadológica.

Este caso expõe dados e falas verídicas da empresa estudada, extraídas de fontes primárias, conforme item fonte de dados.

\section{Objetivos educacionais}

Este caso tem como objetivo geral fornecer elementos que possibilitem aos alunos analisar situações que envolvam práticas cotidianas e tomada de decisões na empresa, pensando e trazendo alternativas para a solução do dilema maior do caso. Os alunos poderão se colocar tanto no lugar do empresário como do terceirizado, analisando quais alternativas e estratégias podem ser adotadas para solucionar o fato ocorrido.

\section{Estratégias para análise do caso}

Para melhor aproveitamento do caso como estratégia de ensino, sugere-se que sejam abordados previamente, em aula, conceitos sobre estratégia organizacional. A leitura do caso deverá acontecer previamente, como tarefa escolar da aula anterior. Para a aplicação do caso propriamente dito, torna-se relevante que ela ocorra em dois momentos distintos. Primeiramente, o caso deverá ser discutido em pequenos grupos, que abordarão as questões de número 1, 2 e 3. Em seguida, pode ser realizado um debate em grande grupo, em que os alunos deverão posicionar-se a partir das respostas desenvolvidas na discussão.

Além das informações contidas no caso, é importante que os alunos sejam estimulados a buscar informações adicionais em outras fontes, especialmente relacionadas a centros automotivos, setor relacionado à organização.

Sugestão para o professor: No momento da aplicação do caso, os alunos podem pesquisar previamente informações e verificar a atual situação da organização. Sugere-se, ao professor, começar a discussão do caso resgatando as teorias sobre estratégia organizacional, processo de tomada de decisão (Mintzberg, 1976), Análise SWOT (Forças, Fraquezas, Ameaças e Oportunidades), estratégias genéricas de Porter (1980), fazendo inter-relação entre os conceitos e sua aplicabilidade ao caso ora proposto. Após isto, pode-se dividir a classe em dois grandes grupos: um grupo representando Rogério Cunha, e outro grupo representando Alberto. A seguir, iniciar o processo de leitura e discussão com base no papel desempenhado por ambos. Os alunos deverão apresentar argumentos sobre os papéis de Rogério e Alberto, fazendo a contraposição dos diversos pontos a serem propostos e discutidos.

\section{Fontes de dados}

O presente caso de ensino é uma história real, com base em entrevista pessoal com o sócio proprietário do CG Centro Automotivo, Sr. Rogério da Cunha (nome fictício), empreendimento localizado na cidade de Florianópolis/SC. Como o caso tem fins didáticos, os nomes foram adaptados ao longo do texto, mas as situações vivenciadas pelos personagens são reais e preservadas para manter a veracidade do caso.

\section{Informações}

O caso é real e as informações foram obtidas por meio de entrevista com o personagem principal. Este caso foi estruturado conforme recomendação de Roesch \& Fernandes (2007) e apresenta o formato de um caso de ensino, conforme quadro 1. 
Quadro 1. Dimensão do caso

\begin{tabular}{|l|c|l|l|l|}
\hline Dimensão & $\begin{array}{c}\text { Nível de } \\
\text { Estruturação }\end{array}$ & \multicolumn{1}{|c|}{$\begin{array}{c}\text { Informações } \\
\text { Apresentadas no Caso }\end{array}$} & $\begin{array}{c}\text { Explicação } \\
\text { do Nível de } \\
\text { Dificuldade }\end{array}$ & \multicolumn{1}{|c|}{ Propósito } \\
\hline Analítica & 3 & $\begin{array}{l}\text { O caso apresenta situação } \\
\text { e contexto ambiental de } \\
\text { análise e definição. }\end{array}$ & $\begin{array}{l}\text { Os alunos poderão } \\
\text { desempenhar papéis } \\
\text { relativos a vários } \\
\text { atores do caso. }\end{array}$ & $\begin{array}{l}\text { Espera-se que o aluno desenvolva } \\
\text { habilidades de desempenhar papéis } \\
\text { que não lhes sejam familiares, } \\
\text { mas que tenham que encontrar } \\
\text { provável desfecho em meio a um } \\
\text { ambiente competitivo. }\end{array}$ \\
\hline Conceitual & 2 & $\begin{array}{l}\text { Combina conceitos de } \\
\text { relativa dificuldade. }\end{array}$ & $\begin{array}{l}\text { Exige leitura prévia e e } \\
\text { aula expositiva. }\end{array}$ & $\begin{array}{l}\text { Vivenciar uma situação real, por } \\
\text { meio da identificação e utilização } \\
\text { de conceitos teóricos e práticos de } \\
\text { uma organização. }\end{array}$ \\
\hline Apresentação & 1 & $\begin{array}{l}\text { As informações são } \\
\text { apresentadas de forma } \\
\text { clara, por meio de } \\
\text { exposição dos fatos, e são } \\
\text { de fácil entendimento. }\end{array}$ & $\begin{array}{l}\text { O caso pode ser } \\
\text { lido em sala de } \\
\text { aula, sendo que } \\
\text { são necessárias } \\
\text { informações } \\
\text { complementares } \\
\text { para os alunos } \\
\text { conhecerem a } \\
\text { atual situação da } \\
\text { organização. }\end{array}$ & $\begin{array}{l}\text { Fazer a integração entre conceitos } \\
\text { e articular teoria e prática } \\
\text { vivenciada nas organizações. }\end{array}$ \\
\hline
\end{tabular}

Fonte: As autoras, adaptado de Roesch \& Fernandes (2007).

\section{Questões para discussão}

1 - Segundo os três modos de elaboração de estratégia apresentados por Mintzberg (1976), analise como a CG elabora as suas estratégias.

2 - Faça uma análise SWOT (Forças, Fraquezas, Ameaças e Oportunidades) das situações enfrentadas por Rogério a partir da terceirização no setor de aros e pneus.

3 - Avaliando as três estratégias genéricas de Porter (2004), qual(is) alternativa(s) Rogério poderia adotar após a saída de Alberto?

\section{Revisão de literatura e análise do caso}

QUESTÃO 1: Segundo os três modos de elaboração de estratégia apresentados por Mintzberg (1976), analise como a CG elabora as suas estratégias

Mintzberg (1973) apresenta três modos para o desenvolvimento e elaboração da estratégia, partindo da reflexão de como as organizações tomam decisões e como estas decisões formam as suas estratégias. $\mathrm{O}$ autor observou, então, que o processo de formação das estratégias poderia ocorrer de três modos distintos: o empreendedor, o adaptativo e o de planejamento.

No modo empreendedor, a construção de estratégias é dominada pela atividade de busca de novas oportunidades, com o poder extremamente centralizado nas mãos de um líder (geralmente de personalidade forte), motivado pela realização de objetivos considerados por ele como essenciais para a organização. Este líder, desse modo, assume todos os riscos de suas ações em nome do que considera melhor para a sua organização, inclusive em momentos de crise, quando ele geralmente não procura por segurança, mas costuma arriscarse ainda mais. As organizações que seguem o modo empreendedor na formulação da sua estratégia buscam novas oportunidades, tendo uma orientação mais ativa do que passiva. Assim sendo, são caracterizadas pela sua ousadia, mesmo diante das incertezas. Deste modo, a empresa que segue este modelo busca atingir, como meta central, o crescimento organizacional (Mintzberg, 1973). 
Já o modo adaptativo é formado por um conjunto de influenciadores organizacionais, os quais possuem força política e formam redes de decisão (sindicatos, diretores, agências reguladoras, entre outros). O estrategista, deste modo, toma decisões mais paliativas, não se distanciando muito do status quo, e suas decisões são negociadas com todos os envolvidos e, consequentemente, influenciadas por eles. A organização dá pequenos e desconexos passos, barganhando as decisões em uma perspectiva de curto prazo e adaptando-se às dificuldades encontradas no seu ambiente. Assim, no modo adaptativo, a organização não possui metas, trabalhando em meio à dificuldade imposta pelo ambiente, em que ocorrem muitos problemas e crises. Nesse contexto, a formação da estratégia é caracterizada mais por soluções reativas aos problemas do que pela busca por oportunidades, avançando aos poucos e deixando a empresa sem uma orientação estabelecida (Mintzberg, 1973).

No modo planejador, o gestor desempenha o papel de analista que se utiliza de métodos específicos para desenvolver planos estratégicos, que levarão à formulação de planos de curto e médio prazos. O analista trabalha em conjunto com os administradores e assume boa parte da responsabilidade pelo processo. Este modo envolve tanto a proativa busca por novas oportunidades quanto a solução de problemas existentes e é comum em organizações de grande porte que estejam inseridas em ambientes altamente competitivos. O processo é realizado de maneira estruturada e sistêmica, por meio de integração de decisões estratégicas. Assim, leva a organização a desenvolver um senso explícito de direção estratégica, por meio de seus valores, princípios, missão e visão estratégica (Mintzberg, 1973).

Contudo, os três modos de formação estratégica apresentados são modelos puros, podendo haver combinações entre eles. No mundo real, é provável que as organizações encontrem alguma combinação dos três modos que reflita melhor as suas necessidades e seus desafios (Mintzberg, 1973).

\section{RESPOSTA À QUESTÃO 1:}

Analisando a estratégia da CG Centro Automotivo, percebe-se que seu método de formação de estratégia não é puro, mas uma mescla dos três modos de elaboração. Isto é descrito pelos fatos e falas apresentadas durante o caso que fomentam, os quais ora apresentam o modo empreendedor, ora apresentam o adaptativo e/ou planejador.

Pode-se confirmar a mescla dos três modos pelo exposto no quadro 2.

Quadro 2 . Modos de formação da estratégia

\begin{tabular}{|c|c|c|}
\hline Modo estratégico & Ligação com a estrutura teórica & Apresentação no Caso \\
\hline Modo Empreendedor & $\begin{array}{l}\text { 1) Poder extremamente centralizado } \\
\text { nas mãos de um líder (geralmente de } \\
\text { personalidade forte). } \\
\text { Fonte: Mintzberg (1973). } \\
\text { 2) Motivado pela realização de objetivos } \\
\text { considerados por ele como essenciais para a } \\
\text { organização. } \\
\text { Fonte: Mintzberg (1973). } \\
\text { 3) O estrategista assume todos os riscos } \\
\text { de suas ações em nome do que considera } \\
\text { melhor para a sua organização, inclusive } \\
\text { em momentos de crise, em que geralmente } \\
\text { não procura por segurança, mas costuma } \\
\text { arriscar-se ainda mais. } \\
\text { Fonte: Mintzberg (1973) }\end{array}$ & $\begin{array}{l}\text { 1) [...] algumas empresas desistirem da parceria, pela } \\
\text { diferença entre a forma de gestão empresarial do gestor } \\
\text { terceirizado e do gestor da CG, ou seja, dificuldade de } \\
\text { trabalhar em conjunto. } \\
\text { 2) A empresa começou a crescer e, em 1998, resolve } \\
\text { mudar o seu segmento, aplicando mudanças estratégicas } \\
\text { também ao corpo diretor da empresa, passando a } \\
\text { comercializar somente acessórios automotivos. } \\
\text { 3) Rogério, sempre teve um espírito empreendedor, } \\
\text { garra, determinação e força de vontade e, ao se deparar } \\
\text { com aquela situação ruim, pensou em terceirizar alguns } \\
\text { setores. }\end{array}$ \\
\hline
\end{tabular}




\begin{tabular}{|c|c|c|}
\hline Modo Adaptativo & $\begin{array}{l}\text { 4) Complexas faces, com rápidas } \\
\text { transformações no ambiente. } \\
\text { Fonte: Mintzberg (1973). } \\
\text { 5) As decisões são negociadas com todos } \\
\text { os envolvidos e, consequentemente, } \\
\text { influenciadas por eles. } \\
\text { Fonte: Mintzberg (1973). } \\
\text { 6) Adapta-se às dificuldades encontradas no } \\
\text { seu ambiente. } \\
\text { Fonte: Mintzberg (1973). } \\
\text { 7) Carece de metas, trabalhando na } \\
\text { dificuldade que o ambiente lhe impõe com } \\
\text { muitos problemas e crises, e a formação da } \\
\text { estratégia é caracterizada mais por soluções } \\
\text { reativas aos problemas. } \\
\text { Fonte: Mintzberg (1973). }\end{array}$ & $\begin{array}{l}\text { 4) Naquela época, era interessante o comércio direcionado } \\
\text { aos argentinos, pois sua moeda estava muito valorizada; } \\
\text { com isso, aumentou o número de turistas, os quais se } \\
\text { tornaram consumidores em potencial da CG. } \\
\text { 5) [...] havendo uma troca entre as empresas, pois o } \\
\text { cliente, que inicialmente vinha consumir acessórios, } \\
\text { descobria que existia uma gama de outros produtos e } \\
\text { serviços, e vice-versa. } \\
\text { Agregando o mix produtos e serviços, assim como a } \\
\text { própria empresa também aprendeu muito com o gestor } \\
\text { terceirizado [...]. } \\
\text { 6) [...] já que o seu mix de produtos não era mais tão } \\
\text { interessante, pois o mercado havia mudado as suas } \\
\text { necessidades. } \\
\text { [‥] a estratégia de terceirização deu muito certo, pois } \\
\text { essas empresas parceiras tinham respaldo e credibilidade } \\
{[\ldots . .] \text {. }} \\
\text { 7) [...] mas a empresa não estava preparada para crescer } \\
\text { tanto e tão rapidamente, começando a surgir alguns } \\
\text { problemas na área administrativa. A consequência } \\
\text { isso foi uma crise financeira na empresa, em } 2005 \text {, } \\
\text { que passou por grandes dificuldades na gestão } \\
\text { administrativa e reduziu o quadro de } 65 \text { funcionários } \\
\text { para } 13 \text {, com o objetivo de evitar a falência. } \\
\text { [...] Existiam cinco terceirizados, sendo que um único } \\
\text { terceirizado, de aros e pneus, era responsável por mais da } \\
\text { metade do faturamento mensal de todos os terceirizados. }\end{array}$ \\
\hline Modo Planejador & $\begin{array}{l}\text { 8) Fornece uma análise de custo formal e } \\
\text { muitos objetivos, que são operacionais. } \\
\text { Fonte: Mintzberg (1973). } \\
\text { 9) Planos estratégicos de curto e médio } \\
\text { prazos. } \\
\text { Fonte: Mintzberg (1973). } \\
\text { 10) Busca por novas oportunidades quanto à } \\
\text { solução de problemas existentes. } \\
\text { Fonte: Mintzberg (1973). } \\
\text { 11) Estão inseridas em ambientes altamente } \\
\text { competitivos. } \\
\text { Fonte: Mintzberg (1973). }\end{array}$ & $\begin{array}{l}\text { 8) A quase falência obrigou o gestor Rogério a diminuir } \\
\text { os custos da empresa, mantendo um faturamento } \\
\text { mínimo para sobreviver e pagar as obrigações. } \\
\text { 9) Além da empresa ter que enxugar o número } \\
\text { de colaboradores, ela precisou se reinventar, } \\
\text { reestruturando-se drasticamente, para poder se manter } \\
\text { no mercado. } \\
\text { 10) [...] o gestor enxergou a oportunidade de oferecer } \\
\text { produtos e serviços para unir e agregar ao seu mix e foi } \\
\text { buscar parceiros nos segmentos. } \\
\text { 11) A empresa do outro lado da rua já estava funcionando } \\
\text { a pleno vapor, oferecendo, além de aros e pneus, } \\
\text { acessórios e mecânica, enquanto a empresa de Rogério } \\
\text { estava sem o setor de aros e pneus para ofertar aos } \\
\text { clientes. }\end{array}$ \\
\hline
\end{tabular}

Fonte: As autoras, adaptado de Mintzberg (1973). 
QUESTÃO 2: Faça uma análise SWOT (Forças, Fraquezas, Ameaças e Oportunidades) das situações enfrentadas por Rogério a partir da terceirização no setor de aros e pneus

A Administração Estratégica pode ser definida como sendo um processo contínuo e que necessita de interação entre a organização e seu ambiente, tanto interno quanto externo (Ansoff, 2013). Para a adequada formulação da estratégia, torna-se imprescindível que seja feita a análise ambiental, chamada também de Análise SWOT. Ela é dividida em: externa (oportunidades e ameaças) e interna (forças e fraquezas). Num primeiro estágio, analisa-se o ambiente externo, identificando as oportunidades de mercado e o enfretamento das ameaças. Num segundo estágio, deve-se analisar a empresa no âmbito interno, verificando as forças, que são os aspectos que a empresa domina, e as fraquezas, que é onde a organização tem potencial de risco (Andrews, 1992).

Segundo Kotler (2000), a análise SWOT monitora forças importantes nos macroambientes (externo), assim como nos microambientes (interno). Para melhor compreensão, segue uma ilustração da matriz SWOT, conforme o quadro 3.

Quadro 3 . Análise SWOT

\begin{tabular}{|c|c|c|c|}
\hline : & Forças & Oportunidades & $\frac{\overrightarrow{3}}{0}$ \\
\hline है & Fraquezas & Ameaças & 8 \\
\hline
\end{tabular}

Fonte: Kotler (2000).

Neste aspecto, de acordo com as probabilidades e gravidades de ocorrências, podem ser geradas matrizes que apontam as oportunidades e ameaças, e a seguir devem ser formuladas listas de verificação para analisar as forças e fraquezas. Na Análise SWOT, deve-se verificar no:

\section{Ambiente externo:}

Oportunidades: definição dos pontos positivos que são controláveis pela empresa e que contribuem como potencial vantagem competitiva da empresa;

Ameaças: definição dos pontos negativos que não são controláveis pela empresa e que contribuem ao comprometimento da vantagem competitiva da empresa.

\section{Ambiente interno:}

Força: definição das vantagens internas da empresa que são controláveis por ela, comparadas às vantagens de seus concorrentes;

Fraqueza: definição das desvantagens internas da empresa que não são controláveis por ela, comparadas às desvantagens de seus concorrentes.

\section{Respostas à questão 2:}

A partir do caso, pode-se fazer a análise SWOT da empresa CG Centro Automotivo, inicialmente procedendo à análise do ambiente externo, como segue:

Oportunidades: características empreendedoras do gestor do Centro; marca conhecida no setor em que atua; redução de custos em relação aos seus concorrentes; assumir o mix de produtos/serviços dos terceirizados; realização dos serviços com equipe própria;

Ameaças: proximidade da concorrência; empresa concorrente com as mesmas características físicas do Centro; perda de clientes.

A seguir, far-se-á a análise do ambiente interno, como segue:

Força: assume o setor com equipe própria; exclusividade de serviços dos terceirizados dentro do Centro; comercialização de produtos e serviços automotivos; acordo entre os terceirizados no mix de produtos/serviços oferecidos; o centro pode investir no ramo desligado, seja por investimento próprio ou na contratação de outro parceiro; pagamento do aluguel do espaço proporcional ao faturamento; espaço físico;

Fraqueza: o aperfeiçoamento da equipe, simultânea ao atendimento do público; o Centro não poderia solicitar o desligamento de terceirizados para oferecer o mesmo serviço; a empresa terceirizada pode solicitar o desligamento a qualquer momento; o setor de aros e pneus representava o maior aluguel do espaço 
terceirizado; custo alto do Centro; perda de colaboradores.

A Análise SWOT do CG Centro Automotivo pode ser representada conforme o quadro 4.

Quadro 4 . Análise SWOT

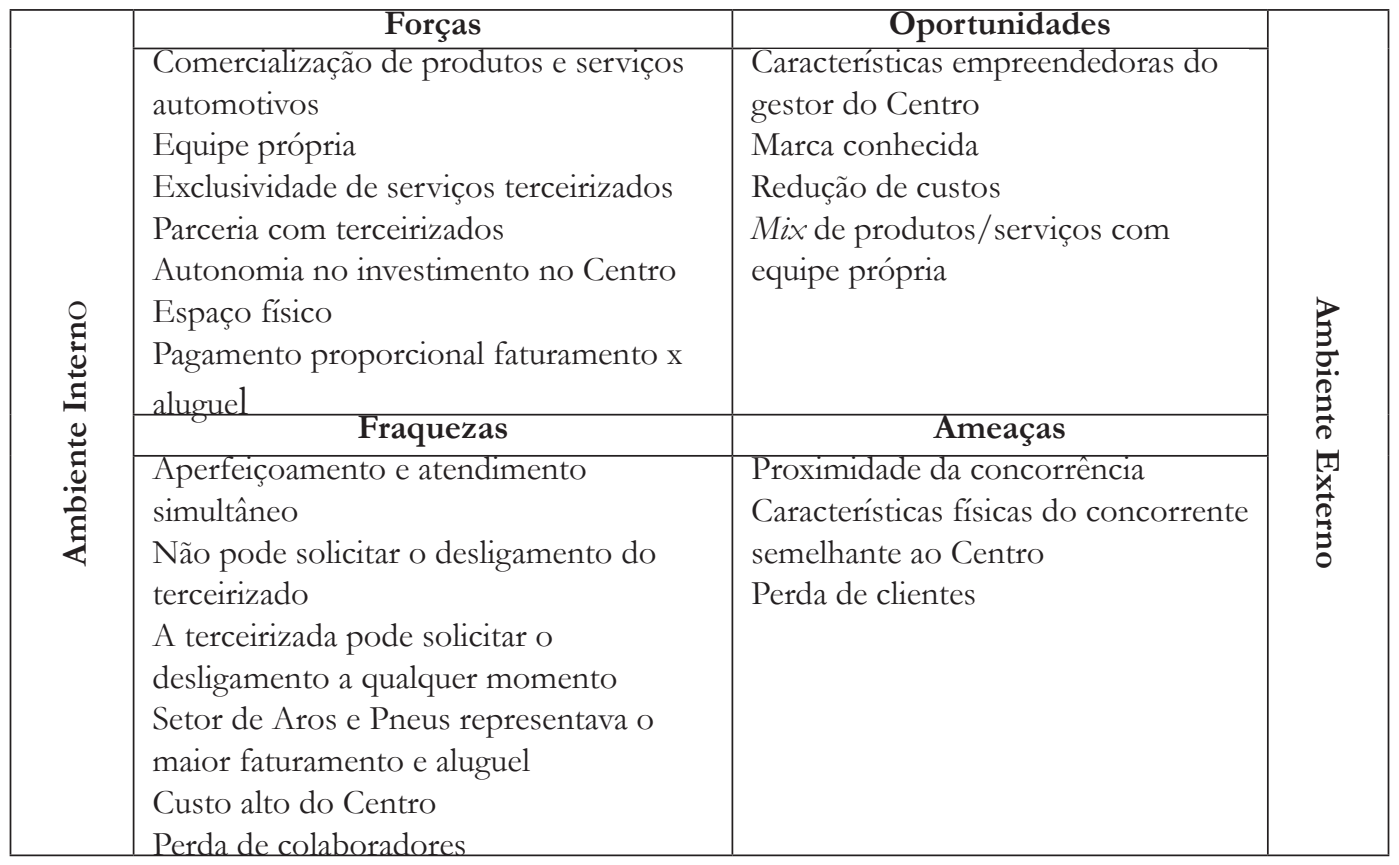

Fonte: As autoras, adaptado de Kotler (2000).

A partir da análise SWOT, o CG Centro Automotivo pode elaborar estratégias para melhorar o desempenho interno e ainda enfrentar a concorrência buscando uma nova posição no mercado (Pereira, 2011).

\section{QUESTÃO 3: Avaliando as três estratégias genéricas de Porter (2004), qual(is) alternativa(s) Rogério poderia adotar após a saída de Alberto?}

Para Porter (2004), existem três estratégias genéricas potencialmente bem-sucedidas, sendo elas: liderança no custo total, diferenciação e enfoque.

Essas estratégias foram criadas com o objetivo de apresentar soluções para as cinco forças competitivas desenhadas pelo autor. Dessa forma, o autor identificou três estratégias genéricas que podem ser utilizadas pelas empresas a fim de conseguirem uma boa posição no mercado em longo prazo e superarem os concorrentes (Porter, 2004).

Segundo Porter (2004), as empresas que apresentariam melhor desempenho e maior sucesso seriam aquelas que conseguissem aplicar uma das três estratégias genéricas. As empresas que utilizassem uma estratégia mista ou que fracassassem na busca por uma das três estratégias foram designadas de meio termo e não teriam a estratégia de defesa.

Para as empresas que se fixam no meio termo, é quase garantida uma baixa rentabilidade: ou elas perdem clientes de grandes volumes (preços baixos), ou perdem seus lucros para colocar seu negócio fora do alcance das empresas de baixo custo. 


\section{Estratégia de Liderança no Custo Total}

Ela exige redução de custo pela experiência; controle rígido do custo e despesas; não permite a formação de contas marginais dos clientes; intensa atenção administrativa ao controle dos custos; minimização do custo em força de vendas, assistência, publicidade. É necessário reduzir e controlar todos esses fatores, já que o tema central da estratégia é o custo baixo em relação aos concorrentes (Porter, 2004).

A posição de baixo custo permite que a empresa receba retornos acima da média e defende-a contra a rivalidade dos concorrentes, pois os seus custos mais baixos mostram que ela ainda pode obter retornos após seus concorrentes obterem lucros na competição. O baixo custo também proporciona defesa contra fortes fornecedores, acarretando em uma maior flexibilidade para encarar os aumentos no custo dos insumos.

Geralmente a posição de baixo custo insere a empresa em uma posição favorável quando relacionada aos produtos dos seus concorrentes. Colocando em prática a estratégia de baixo custo, a empresa pode demandar investimento pesado de capital em equipamento atualizado, fixação de preço agressiva e prejuízos iniciais até consolidar a parcela de mercado.

Por outro lado, quando atingida a posição de baixo custo, existirão maiores margens que podem ser reinvestidas em modernos equipamentos e/ou instalações, com o objetivo de manter a liderança de custo.

\section{Estratégia de Diferenciação}

Essa estratégia genérica preocupa-se em diferenciar o produto ou serviço oferecido pela empresa, criando algo inovador e único dentro do mercado, cujas características a distingam do produto do concorrente (Porter, 2004).

Existem alguns métodos para essa diferenciação: projeto ou imagem da marca, tecnologia, serviços sob encomenda, rede de fornecedores. Se a empresa conseguir atingir a diferenciação, ela terá uma estratégia viável para obter retornos maiores do que a média. Além disso, fornece isolamento contra a rivalidade competitiva, já que existe uma lealdade dos consumidores com a marca.

A empresa que se diferencia gera um sentimento de exclusividade, que é incompatível com a alta parcela do mercado e também com os custos baixos e preços comparáveis aos da concorrência. Por isso, é preciso atentar à precificação dos produtos ou serviços, para não supervalorizá-los.

\section{Estratégia de Enfoque}

Segundo Porter (2004), essa estratégia foca em um certo grupo comprador, num segmento de produtos ou mercado geográfico. A estratégia de enfoque tem como objetivo atender muito bem o alvo determinado, e cada política é desenvolvida levando isso em consideração. Baseia-se na premissa de que a empresa pode atender seu alvo estratégico de maneira mais efetiva ou eficientemente, se comparada aos concorrentes que estão competindo de modo mais amplo.

Desenvolvendo-se com sucesso a estratégia de enfoque, é possível obter retornos acima da média, fazendo com que a empresa tenha uma posição de baixo custo com seu alvo estratégico, e alta diferenciação, ou os dois. Essa estratégia implica em certas limitações na parcela total de mercado que pode ser atingida.

Uma empresa tem, portanto, três opções estratégicas - liderança de custos, diferenciação ou enfoque (dividida em duas subopções - foco no custo ou foco na diferenciação), conforme mostra a figura 1 .

Figura 1. Vantagem Estratégica de Porter

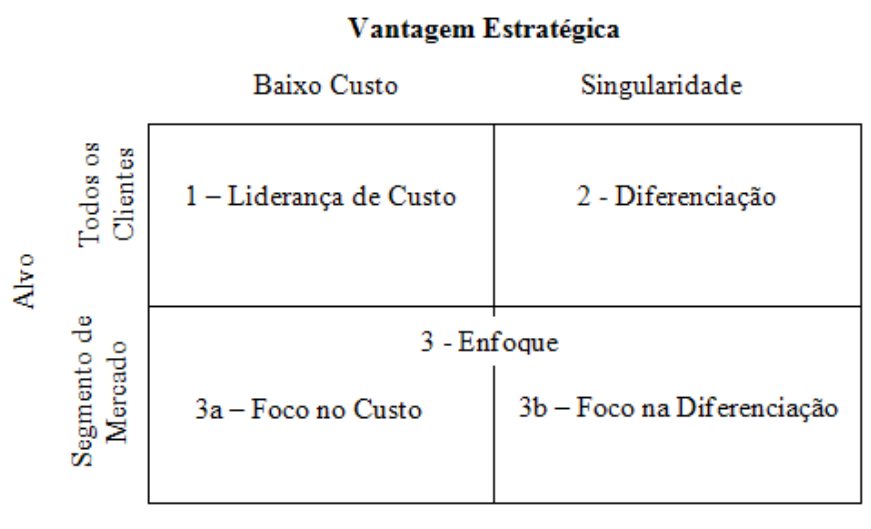

Fonte: Adaptado de Porter (2004).

\section{Resposta à questão 3:}

Rogério utilizou, após a saída de Alberto, a estratégia de liderança no custo total. Nesse sentido, a empresa CG tornou seu custo total menor que o de seus concorrentes, funcionando como mecanismo de defesa contra a rivalidade de seus concorrentes, 
especialmente no âmbito de preços dos produtos e serviços oferecidos.

Logo após a saída do setor de aros e pneus, Rogério elaborou a estratégia de comercializar seus produtos e serviços por preços inferiores aos do mercado vigente na época, o que atraiu muitos clientes para o centro automotivo.

Devido à implantação dessa estratégia, Rogério designou atividades de intenso controle ao departamento responsável pelos custos e despesas, havendo minimização dos custos menos prioritários, corte de gastos, entre outros.

\section{Desfecho da situação do cg centro automotivo}

Rogério viu-se em uma situação complicada. Como não tinha know how para desenvolver o setor de aros e pneus, pensou em modernizá-lo, fazendo um investimento em reforma e tornando o ambiente mais bonito. Por isso, o gestor modernizou e deixou o setor de aros e pneus funcionando, mesmo que de forma amadora, só para poder mostrar ao mercado que ele não tinha parado de funcionar.

Dessa forma, tornou o setor mais atrativo, de forma a conseguir um terceirizado forte para assumir esse setor. Se o setor parasse, o negócio de Alberto ganharia muita força e a empresa de Rogério iria regredir muito rapidamente. Então, no momento em que Alberto avisou que iria sair, Rogério já colocou funcionários próprios para atuarem no setor.

Rogério começou a estudar muito o setor, desenvolver estratégias. Viajou para São Paulo e visitou mais de cinco empresas renomadas no ramo, conhecendo e estudando o segmento, descobrindo que era uma boa área e não era tão complexa quanto imaginava, apesar de necessitar de capital de giro, pois o investimento em estoque era muito alto.

Não conseguindo encontrar um terceirizado à altura do anterior, até porque ninguém queria bancar aquela aposta da concorrência forte (uma loja especializada em aros e pneus em frente), a única alternativa viável para Rogério foi assumir o setor.

Após seis meses, depois de toda uma análise, Rogério resolveu investir com recursos próprios nesse segmento. A partir do conhecimento do produto e serviço oferecido, captou profissionais capacitados no mercado e tocou o negócio.

Durante o desenvolvimento do negócio, percebeu que o setor de aros e pneus dependia de outros serviços complementares para ser lucrativo, sendo que o setor de mecânica continuava sendo terceirizado por Júlio, que trazia uma receita muito baixa. Além disso, Júlio e Rogério possuíam uma forma muito diferente de trabalhar.

Rogério percebeu que, quando vendia aros e pneus, precisava da mecânica para dar continuidade ao serviço, chegando à conclusão de que o setor de mecânica também precisava deixar de ser terceirizado e tornar-se próprio.

Mas como a mecânica iria deixar de ser terceirizada? Como não ser antiético e não prejudicar a empresa de Júlio? Já que havia um contrato relatando que a empresa não poderia tirar um terceirizado e montar o mesmo segmento no lugar.

Rogério marcou uma reunião com Júlio, os dois conversaram e negociaram que, em um prazo de seis meses, Júlio iria encontrar outro ponto, estrutura-se, estabelecer-se, migrar sua clientela para outro lugar e ter vida própria, para então, após esse período e todo esse processo, a CG poder assumir aquele setor.

Com todas essas mudanças, no ano de 2013 a empresa se reinventou, passou por uma grande reforma física e profissionalizou sua equipe. Atualmente, essa empresa de mecânica atua em outro local, é conceituada no mercado, está bem estabelecida, e os dois gestores possuem uma boa relação. Assumindo também esse setor, o Centro Automotivo conseguiu dominar a mecânica, especializando-se e tendo conhecimento na área.

Antigamente, vendia-se de 300 a 400 pneus mensalmente pelo terceirizado e, atualmente, vendese cerca de 1.200 pneus por mês pela própria empresa, ou seja, triplicou-se a quantidade de vendas devido à nova estratégia adotada.

No setor de mecânica, onde havia quatro elevadores automotivos (elevacar), com faturamento médio de $\mathrm{R} \$$ 40.000,00, atualmente tem-se 14 elevacar, conseguindo atender a 14 carros ao mesmo tempo, com um faturamento mensal de $\mathrm{R} \$ 150.000,00$.

Atualmente, apenas os setores de martelinho de ouro e lataria e pintura continuam terceirizados, sendo que expandiram e cresceram muito. São serviços próprios da empresa CG o setor de acessórios, aros e pneus e mecânica, contando com 52 funcionários próprios e dez terceirizados. 
O Centro Automotivo passou por mais mudanças em 2016, inclusive mudou seu layout e sua estrutura física para se diferenciar da empresa vizinha, o novo concorrente. Atualmente, a CG é considerada líder de mercado, atendendo a cerca de cem veículos por dia.

\section{Referências}

Andrews, K. R. The concept of corporate strategy. In: Mintzberg, H., \& Quinn, J. B. (1992). The strategy process. Prentice-Hall, p. 44-51.

Ansoff Matrix: Strategy Skills. (2013). Recuperado em http://www.free-management-ebooks.com/

Kotler, P. (2000). Administração de marketing: a edição do novo milênio. São Paulo/SP: Prentice Hall.

Mintzberg, H. (1973) Strategy-making in three modes. California Management Review, 16 (2).

Mintzberg, H. et. al. (1976) The structure of "instrutured" decision processo In: Administrative Science Quartely, 21 (2).

Pereira, M.F. Administração estratégica. Florianópolis: Departamento de Ciências da Administração / UFSC; [Brasília]: CAPES: UAB, 2011.

Porter, M. E. (1980) Competitive strategy : techniques for analysing industries and competitors. New York : Free Press.

Porter, M. E. (2004). Estratégia competitiva: técnicas para análise de indústrias e da concorrência. (2. ed.) Rio de Janeiro/RJ:Elsevier.

Roesch, S.M.A., \& Fernandes, F. (2007). Como escrever casos para o ensino de administração. São Paulo/SP: Atlas.

\section{Leituras complementares sugeridas}

Ghoshal, S. (2006). O processo da estratégia: conceitos, contextos e casos selecionados. 4. ed. Porto Alegre/ RS: Bookman.

Mintzberg, H. Generic strategies: toward a comprehensive framework. In: Shrivastava, P. (Ed.). Advances in strategic management. Greenwich, Conn.: Jay Press, 1988. v.5. p.1-67.

Mintzberg, H., \& Quinn, J. B. (2001) O processo da estratégia. 3. ed. Porto Alegre/RS: Bookman. 